\title{
Cisternas para armazenamento de água de chuva e efeito na diarreia infantil: um estudo na área rural do semiárido de Minas Gerais
}

\section{Rainwater cisterns and its effect in children diarrhoea: a study in semi arid rural area at Minas Gerais}

\author{
Carolina Ventura da Silva \\ Nutricionista pela Universidade Federal de Viçosa. Mestre e Doutora em Saneamento, Meio Ambiente e Recursos Hídricos pela Universidade Federal de \\ Minas Gerais (UFMG) - Belo Horizonte (MG), Brasil.
}

\begin{abstract}
Léo Heller
Engenheiro Civil. Mestre em Engenharia Sanitária. Doutor em Epidemiologia. Pós-doutorado pela Universidade de Oxford, Inglaterra. Professor associado do Departamento de Engenharia Sanitária e Ambiental da UFMG - Belo Horizonte (MG), Brasil.

\section{Mariângela Carneiro}

Farmacêutica e Bioquímica. Mestre em Parasitologia e Doutora em Parasitologia, área de Epidemiologia das Doenças Infecciosas e Parasitárias pela UFMG. Pós-Doutorado em Epidemiologia na Johns Hopkins University, School of Hygiene and Public Health. Professora associada da UFMG - Belo Horizonte (MG), Brasil.
\end{abstract}

\section{Resumo}

O estudo avaliou a prevalência de diarreia em crianças menores de 60 meses, segundo o tipo de abastecimento de água utilizado. Foi conduzido estudo epidemiológico, seguindo o delineamento quase-experimental, com 664 crianças, sendo 332 moradoras de residência que têm cisterna e 332 que utilizam água de outra fonte. A variável dependente foi a ocorrência de diarreia nas últimas 72 horas; as outras informações foram obtidas por meio da aplicação de questionários estruturados. A prevalência total de diarreia foi de 5\%, porém sem diferença significativa entre os grupos. As variáveis que explicaram a morbidade foram o grupo, a idade da criança, a ingestão de vitamina ou fortificante, e o local de descarte das fraldas sujas com fezes da criança. Não houve diferença significativa entre os grupos na avaliação da qualidade microbiológica da água, ou seja, o uso de água de chuva pode não ter proporcionado melhorias no acesso à água de melhor qualidade quando comparado com as outras fontes utilizadas. No entanto, há que se considerar falhas nos cuidados, no manuseio e no tratamento da água adotados. Destaca-se a necessidade de melhoria das práticas sanitárias da população do meio rural para que a higiene pessoal, domiciliar e em relação à água consumida sejam incorporadas como hábitos rotineiros.

Palavras-chave: abastecimento de água; água de chuva; cisterna; diarreia; saneamento rural.

\begin{abstract}
The present text evaluated the diarrhea prevalence in children under 60 months, according to water supply. An epidemic study was conducted with quasiexperimental design with 664 children, 332 who lived in residence that had cistern and 332 that use water from another source. Diarrhoea occurrence in the last 72 hours was the dependent variable, the others informations were obtained by structured questionnaires. Total diarrhoea prevalence was of $5 \%$, however with no significant difference among the groups. The variables that explained the disease were child's age; if it was taking vitamin and where the dirty diapers with the child's feces were displaced. There were no significant difference among the groups in water microbiological analyses; in other words, the use of rainwater had might not provided improvements in the access of a better quality water supply when compared with the other alternative sources. However, it has to be considered faults in handling and water treatment. It stands out the need of sanitary practices improvement of rural area population, so that personal and home hygiene and in relation to consumed water could be incorporated as routine habits.
\end{abstract}

Keywords: cistern; diarrhoea; rain water; rural sanitation; water supply. 


\section{Introdução}

Apesar dos avanços nas áreas da Medicina e do Saneamento, a diarreia ainda é considerada um problema rotineiro da saúde pública. São cerca de 2,5 bilhões de casos de diarreia anuais em crianças com idade inferior a cinco anos, em todo o mundo, levando a 1,5 milhão de mortes por ano (WHO, 2009). No Brasil, segundo os dados da Monitorização das Doenças Diarreicas Agudas (MDDA), do Ministério da Saúde, de 2000 a 2010, foram notificados mais de 29 milhões de casos, tendo a Região Nordeste apresentado o maior número, 39\%, e a Região Sul, $9 \%$ dos casos ${ }^{1}$.

A diarreia é um sintoma de diversas etiologias, cada uma com seus respectivos fatores de risco; os determinantes são múltiplos, compondo uma complexa cadeia causal (HELLER, 1997). A morbidade é utilizada como indicador epidemiológico de grande importância para a saúde pública, pois sua ocorrência é associada a um conjunto de fatores de natureza socioeconômica, cultural, nutricional e ambiental, respondendo a diversas alterações nas condições de saneamento, qualidade sanitária dos alimentos, hábitos higiênicos e comportamentais (HELLER, 1997; MORAES, 1997).

A associação da diarreia com a qualidade e/ou quantidade da água já foi evidenciada em vários estudos, nos quais foram enfatizados os benefícios das intervenções em saneamento; há relatos da redução média de 15 a 17\% nos casos de diarreia decorrentes da melhoria na qualidade da água (ESREY; FEACHEM; HUGHES, 1985; ESREY et al., 1991; HELLER, 1997; FEWTRELL et al., 2005; CLASEN et al., 2007).

Entretanto, apesar do reconhecimento da importância do fornecimento de água em quantidade e qualidade adequadas para o consumo humano, a fim de minimizar a ocorrência de doenças relacionadas a ela, ainda persiste a discrepância no seu acesso, que pode ser considerada elevada. Se em grandes centros urbanos do Brasil o abastecimento de água pode estar próximo à universalidade (BRASIL, 2004), em pequenos municípios e em áreas rurais a realidade é ainda distante. Nas áreas rurais, cerca de um terço dos domicílios é abastecido por rede de distribuição e por poço ou nascente com canalização interna (BRASIL, 2011a). Porém, o dado não revela se a água consumida é, necessariamente, segura para o consumo humano. Avaliações da qualidade microbiológica da água de fontes subterrâneas (poços) e subsuperficiais (nascentes) mostram a sua inadequabilidade considerando a presença de indicadores de contaminação fecal, bem como a vulnerabilidade relacionada com o seu manuseio (AMARAL et al., 2003; ROCHA et al., 2006; MALHEIROS et al., 2009).

Tendo em vista o quadro relatado, as doenças de veiculação hídrica ou que têm a água como parte da vida do vetor ainda persistem pela negligência existente com a população rural no que diz respeito às condições de captação e uso da água, quando comparada com a residente nos centros urbanos (ROCHA et al., 2006).

A água de chuva tem sido uma solução alternativa, na maior parte das vezes individual, de abastecimento em áreas rurais, principalmente em regiões áridas e semiáridas, locais em que as fontes disponíveis, como poços, rios e nascentes, dispõem de volume variável de água, sob efeito da sazonalidade. No Brasil, essa solução é adotada há muitos anos no semiárido (DIAS, 2004), no entanto passou a ser mais difundida pela ação do Programa Um Milhão de Cisternas (P1MC), idealizado pela própria sociedade civil, por meio de ONGs, e financiado pelo governo federal.

Vários estudos focaram a qualidade microbiológica da água de chuva, com resultados que, muitas vezes, apontam a presença de indicadores de contaminação fecal e, consequentemente, a classificam como inadequada para o consumo humano se utilizada sem tratamento prévio. Em muitos desses estudos, foi detectada a presença de coliformes termotolerantes ou Escherichia coli (Tabela 1), o que contraria critérios e normas internacionalmente reconhecidos de qualidade da água para consumo humano, os quais estabelecem a ausência desses indicadores de contaminação fecal na amostra destinada ao consumo humano (Tabela 1).

Por outro lado, ainda não há muitos estudos avaliando a associação do uso do sistema de captação de água de chuva como fonte de abastecimento domiciliar e o efeito sobre a saúde. Alguns autores basearam os textos em relatos de surtos de doenças de veiculação hídrica, nos quais o consumo de água de chuva armazenada em cisterna foi apontado como uma das causas prováveis (RODRIGO et al., 2003). No Brasil, três estudos epidemiológicos já foram conduzidos: dois em Pernambuco, com delineamento transversal (MARCYNUK et al., 2007) e de coorte (LUNA, 2011), e um no Ceará, também com delineamento transversal (JOVENTINO et al., 2010). Nos três

Tabela 1 - Estudos que apontaram a presença de indicadores de contaminação fecal em amostras de água de chuva.

\begin{tabular}{|c|c|c|c|}
\hline Autor(es) & Local & $\mathrm{n}$ & $\begin{array}{l}\text { Percentual de amostras com presença de indicador } \\
\text { de contaminação fecal }{ }^{\mathrm{a}}\end{array}$ \\
\hline Amorim e Porto (2001) & Pernambuco & 14 & $100 \%$ das amostras $>1$ coliforme ${ }^{b}$ \\
\hline Simmons et al. (2001) & Nova Zelândia & 125 & $56 \%$ das amostras $>1 \mathrm{CF}$ \\
\hline Brito et al. (2005a) & Pernambuco & 50 & $100 \%$ das amostras $>1 \mathrm{CF}$ \\
\hline Brito et al. (2005b) & Pernambuco & 15 & $73 \%$ das amostras $>1 \mathrm{CF}$ \\
\hline Silva (2006) & Minas Gerais & 112 & $70 \%$ das amostras $>1 \mathrm{EC}$ \\
\hline
\end{tabular}

alnformações obtidas dos estudos; 'Sem especificação; CF: grupo coliformes "fecais" - termo em desuso. Atualmente, o grupo é denominado coliformes termotolerantes; EC: Escherichia coli.

${ }^{1}$ Disponível em <http://portal.saude.gov.br/portal/arquivos/pdf/tabela_casos_dda_04_10_11.pdf>. Acesso em: 13 jun. 2011. 
estudos, foi constatado que o uso de água de chuva armazenada em cisternas pode ser considerado fator de proteção contra a diarreia. Joventino et al. (2010), no entanto, consideram que a água de chuva armazenada nas cisternas pode não ter sido a única responsável pela redução das internações por doenças diarreicas no local de estudo.

Em razão da necessidade de mais pesquisas para verificar se sistemas para captação e armazenamento de água de chuva têm proporcionado melhorias na saúde da população beneficiada, o presente texto apresenta os resultados de um estudo epidemiológico quase-experimental conduzido com crianças com idade inferior a 60 meses, em dois grupos distintos: (a) aqueles que dispunham de cisterna para armazenamento de água de chuva, presente no próprio domicílio ou de vizinhos; (b) aqueles que consumiam água de outras fontes alternativas, como rios e nascentes. A comparação baseou-se na prevalência de diarreia nas últimas 72 horas, informação obtida por meio de perguntas de questionário estruturado.

\section{Metodologia}

\section{Delineamento e definição da amostra}

Os trabalhos de campo foram realizados de setembro a dezembro de 2009, em comunidades rurais de dois municípios do Médio Vale do Jequitinhonha, Minas Gerais: Berilo e Chapada do Norte. O delineamento adotado para o estudo foi o quase-experimental; os dados foram tratados seguindo o delineamento transversal.

Para avaliar o efeito da implantação do sistema de captação de água de chuva no domicílio, foi feita seleção não aleatória de crianças com idade inferior a 60 meses, residentes na área rural de Berilo e Chapada do Norte, classificadas em dois grupos: (1) grupo cisternas - crianças que residiam em domicílios com cisternas para armazenamento de água de chuva ou que utilizassem água proveniente de cisternas de outras residências; (2) grupo outras fontes - crianças que consumiam água proveniente de outras fontes alternativas, como rios, córregos e nascentes.

$\mathrm{Na}$ amostra calculada, foram considerados dados de diarreia consultados na literatura: a prevalência de $20 \%$ de diarreia no grupo não exposto (grupo outras fontes), o intervalo de confiança de $95 \%$, e o poder do teste de $80 \%$ (informações requisitadas pelo programa estatístico para o cálculo de amostra), resultando em 706 crianças. Foram consideradas doentes as crianças que apresentaram algum episódio de diarreia nas 72 horas que antecederam a entrevista. Essa variável foi criada a partir de três questões preexistentes no questionário aplicado da pesquisa: "A criança teve diarreia antes de ontem?", "A criança teve diarreia ontem?" e "A criança está com diarreia hoje?"

A definição de diarreia adotada na pesquisa foi a da Organização Mundial da Saúde (WHO, 1988), em que "considera-se como o início de um episódio de diarreia a ocorrência de pelo menos três evacuações líquidas ou amolecidas em um período de 24 horas, ou seja, desde a hora que a criança acorda em um dia até a hora que acordar no dia seguinte; considera-se o fim do episódio quando houver dois ou mais dias sem apresentar diarreia".

\section{Coleta e análise de dados}

A coleta de dados foi realizada pelos pesquisadores do estudo, acompanhados por Agentes Comunitários de Saúde (ACS) do Programa Saúde da Família (PSF) de cada município. Por meio da aplicação de questionário socioeconômico estruturado, foram obtidas informações relacionadas à família, à residência, à saúde materna e das crianças, e aos hábitos de higiene pessoal e peridomiciliar, as quais foram associadas com os dados obtidos com a prevalência de diarreia; os grupos foram inseridos na associação como uma das variáveis explicativas. As variáveis coletadas foram classificadas em sete subgrupos, para avaliação da associação com a presença da diarreia:

- Estrutura familiar: tempo que a mãe e o pai passam fora do domicílio (meses/ano); quem passa mais tempo cuidando da criança; nível de estudo da pessoa que passa mais tempo com a criança.

- Nível socioeconômico: número de cômodos do domicílio; número de pessoas que residem no domicílio; a casa tem banheiro; se o banheiro é completo; material de construção da casa; material de cobertura da casa; material de piso da casa; se a família recebe algum benefício do governo; renda familiar total.

- Esgotamento sanitário: local onde a família defeca; destino das fraldas sujas de fezes; destino da água de pia/tanque e da água do banho; se há córrego próximo à residência; se as crianças têm contato com o córrego e qual o tipo de contato.

- Resíduos sólidos: o lixo é separado na casa; destino do lixo da casa; destino do lixo da cozinha.

- Vetores: frequência de moscas/mosquitos e baratas na casa durante o ano; frequência de ratos na casa ou próximo a ela durante o ano.

- Hábitos higiênicos: frequência de banho nas crianças; a criança lava as mãos depois de ir ao banheiro; a criança lava as mãos antes de se alimentar; a pessoa que prepara a comida lava as mãos antes; como é feita a higienização de verduras antes do consumo.

- Variáveis relacionadas à saúde da criança e da mãe: sexo; idade da criança; idade da mãe; internação da criança no primeiro mês de vida; vacinação; amamentação (duração); suplementação por vitaminas; ingestão de remédios (anti-inflamatórios, antibióticos, vermicidas); diarreia das crianças nas últimas 72 horas; ordem de gravidez; consulta pré-natal; complicações durante a gravidez.

As características relativas ao abastecimento de água foram apresentadas de forma descritiva, utilizando recursos da estatística. Avaliou-se também a qualidade microbiológica pela concentração de coliformes totais e E. coli nas amostras de água das fontes consumidas 
em ambos os grupos, para auxiliar na discussão dos resultados. A técnica adotada na análise microbiológica das amostras de água foi a do substrato cromogênico definido, recomendada pelo Standard Methods for the Examination of Water and Wastewater (APHA, 2005). Foram selecionadas, aleatoriamente, 100 amostras, sendo 50 em cada grupo, coletadas diretamente do local em que a família retirava água para beber.

Os dados obtidos com os questionários foram explorados primeiramente pela estatística descritiva (n e frequência). Em seguida, foi realizada análise univariada, com o cálculo do qui-quadrado $\left(\chi^{2}\right)$ para as variáveis qualitativas; quando necessário, foi utilizado o teste Exato de Fisher ou a simulação Monte Carlo². Já para as variáveis quantitativas, foi aplicado o teste $U$ de Mann-Whitney. Aquelas que apresentaram $\mathrm{p}>0,20$ foram descartadas, com exceção das que apresentavam alguma relevância para justificar a diarreia.

Finalmente, foi feita a análise multivariada, utilizando-se o Modelo de Regressão Logística Binária. Para seleção das variáveis significativas no modelo final de regressão, partiu-se do modelo completo, com descarte sucessivo das variáveis (backward), utilizando o nível de significância de 0,05.

Os resultados das análises microbiológicas das amostras de água de ambos os grupos foram avaliados de acordo com a Portaria $n^{\circ}$ 2.914/2011 do Ministério da Saúde (BRASIL, 2011b), que

Tabela 2 - Distribuição das crianças (n e \%) por sexo, de acordo com 0 grupo.

\begin{tabular}{lcccc} 
& \multicolumn{4}{c}{ Grupo } \\
\cline { 2 - 5 } Sexo & \multicolumn{2}{c}{ Cisternas } & \multicolumn{2}{c}{ Outras fontes } \\
\cline { 2 - 5 } & $\mathrm{n}$ & $\%$ & $\mathrm{n}$ & $\%$ \\
Feminino & 161 & 48,5 & 156 & 47,0 \\
Masculino & 171 & 51,5 & 176 & 53,0 \\
\hline Total & 332 & 100,0 & 332 & 100,0 \\
\hline
\end{tabular}

A média de idade das crianças no grupo cisternas foi de 26,6 meses (mínimo $=2$ dias e máximo = 56,3 meses); no grupo outras fontes, a média foi de 26,0 meses (mínimo = 2 dias e máximo $=54,0$ meses)

Tabela 3 - Prevalência de diarreia em crianças menores de 60 meses, de acordo com a forma de abastecimento.

\begin{tabular}{|c|c|c|c|c|c|}
\hline \multirow{3}{*}{ Variáveis } & & \multicolumn{4}{|c|}{ Grupo } \\
\hline & & \multicolumn{2}{|c|}{ Cisterna } & \multicolumn{2}{|c|}{ Outras fontes } \\
\hline & & $\mathrm{n}$ & $\%$ & $\mathrm{n}$ & $\%$ \\
\hline \multirow{2}{*}{$\begin{array}{l}\text { Teve diarreia antes } \\
\text { de ontem }\end{array}$} & Sim & 8 & 2,4 & 14 & 4,2 \\
\hline & Não & 323 & 97,6 & 317 & 95,8 \\
\hline \multirow{2}{*}{ Teve diarreia ontem } & Sim & 6 & 1,8 & 14 & 4,2 \\
\hline & Não & 326 & 98,2 & 318 & 95,8 \\
\hline \multirow{2}{*}{ Esta com diarreia hoje } & Sim & 5 & 1,5 & 11 & 3,3 \\
\hline & Não & 326 & 98,5 & 321 & 96,7 \\
\hline \multirow{3}{*}{ Diarreia $^{a}$} & Sim & 12 & 3,6 & 20 & 6,0 \\
\hline & Não & 320 & 96,4 & 312 & 94,0 \\
\hline & Total & 332 & 100,0 & 332 & 100,0 \\
\hline
\end{tabular}

aVariável criada pela união das três questões relacionadas à ocorrência de diarreia. estabelece o padrão de potabilidade da água para consumo humano. Os resultados também foram comparados entre si, por meio da aplicação do teste U não paramétrico de Mann-Whitney, utilizando o nível de 0,05 de significância.

Os dados foram analisados com o uso do programa SPSS 17 (Statistical Package for Social Sciences).

A pesquisa foi aprovada pelo Comitê de Ética em Pesquisa da Universidade Federal de Minas Gerais (COEP/UFMG - ETIC 279/09).

\section{Resultados e Discussão}

\section{Características da amostra}

A amostra atingida pela pesquisa foi de 664 crianças, distribuídas igualmente nos dois grupos, correspondendo a $94 \%$ do que foi calculado inicialmente - 706 crianças. Destas, 317 eram do sexo feminino $(47,74 \%)$ e 347 (52,26\%), do masculino, conforme Tabela 2.

Em relação às questões ligadas à diarreia (Tabela 3), de modo geral, o grupo cisternas apresentou menos casos da doença em relação ao grupo outras fontes. Nota-se que houve baixa prevalência em ambos os grupos, considerando as 72 horas anteriores à data da entrevista: 12 crianças $(3,6 \%)$ que dispunham de cisterna apresentaram diarreia, enquanto esse número foi de 20 (6,0\%) entre as crianças que consumiam água outras fontes, principalmente rio e nascentes (Tabela 3).

A prevalência da diarreia encontrada entre as crianças no presente estudo (média de 5\%, considerando a totalidade da amostra) foi bem inferior à detectada por Marcynuk et al. (2007), em estudo conduzido em Pernambuco, no qual a prevalência geral entre as crianças menores de cinco anos foi de 21,0\%. Comparando as crianças por grupo, as prevalências também foram inferiores: aquelas que tinham cisternas nas residências apresentaram prevalência de 16,1\% e as que não tinham as cisternas, de $25,7 \%$, enquanto no presente estudo, os valores foram 3,6 e 6\%, respectivamente. Porém, deve ser destacado que Marcynuk et al. (2007) avaliaram período maior de diarreia, 30 dias, enquanto no presente estudo o tempo de monitoramento foi de apenas três dias.

É interessante observar que a razão de prevalência bruta foi de 0,60 neste estudo e de 0,62 em Marcynuk et al. (2007). Esses resultados similares estariam evidenciando que as cisternas agem como fator de proteção contra a diarreia.

Por outro lado, quando se comparam os dois estudos em termos de prevalência expressa por episódios/criança. dia $^{3}$, tem-se que o presente estudo mostrou prevalência cerca de três vezes maior que a do outro, tanto para o grupo que se abastecia de água de chuva $(0,0120$

\footnotetext{
${ }^{2}$ Nas tabelas de contingência em que a variável preditora é dicotômica (tabela 2 x 2) e em uma das células o valor é inferior a cinco, é feito o teste de Fisher. A simulação de Monte Carlo é utilizada quando a variável preditora tem mais de duas categorias (tabela 2 x n) e também há valor inferior a cinco.

${ }^{3} \mathrm{O}$ cálculo da prevalência expressa por episódios/criança.dia considerou o número total de episódios de diarreia no grupo observados no período, o número total de crianças do grupo e o tempo de acompanhamento dos episódios de diarreia.
} 
neste estudo e 0,0036 em Marcynuk et al., 2007) quanto para o que se abastecia de outras fontes $(0,0201$ neste estudo e 0,0060 em Marcynuk et al., 2007).

É importante destacar que os valores utilizados para o cálculo do número de episódios/pessoa. dia obtidos do estudo de Marcynuk et al. (2007) foram retirados da amostra total, na qual foram incluídos os indivíduos adultos, sabidamente mais resistentes a doenças de veiculação hídrica, justificando a diferença entre os estudos.

\section{Tratamento estatístico}

\section{Associação entre diarreia e variáveis preditoras}

Por meio da análise univariada, apenas as seguintes variáveis preditoras foram selecionadas para a análise multivariada, considerando $\mathrm{p}<0,20$ :

- Idade da criança $(\mathrm{p}=0,07)$

- Grupo $(\mathrm{p}=0,147)$

- Ainda está sendo amamentado? $(\mathrm{p}=0,156)$

- Está tomando vitamina/fortificante $(\mathrm{p}=0,012)$

- Escolaridade do responsável pelo cuidado da criança $(\mathrm{p}=0,097)$

- Material de piso da casa ( $\mathrm{p}=0,163)$

- Para onde vão as fraldas sujas com fezes da criança? $(p=0,011)$

- Frequência de banho das crianças ( $p=0,110)$

- Lavar as mãos antes de se alimentar ( $p=0,093)$

- Lavar as mãos antes e depois de usar o banheiro ( $p=0,090)$

- A pessoa que prepara a comida lava as mãos antes de iniciar as atividades na cozinha? $(\mathrm{p}=0,186)$

No modelo final, apenas as variáveis grupo, idade da criança, ingestão de vitamina/fortificante e local de descarte das fraldas sujas com fezes da criança permaneceram no modelo para explicar a diarreia. Na Tabela 4, estão apresentadas as variáveis selecionadas na análise multivariada, com as respectivas razões de chance (Odds Ratio (OR)) ajustadas no modelo final (Tabela 4).

Ao analisar as variáveis remanescentes no modelo final da regressão logística (Tabela 4), de acordo com a razão de chances (Odds Ratio) da variável grupo, poder-se-ia dizer que as crianças que viviam em domicílios os quais tinham o sistema de captação de água de chuva, ou utilizavam de vizinhos, apresentaram menor chance $(\mathrm{OR}=0,56)$ de desenvolver diarreia quando comparadas com aquelas que viviam em domicílios abastecidos por água de rio, nascentes, córregos ou cacimbas. No entanto, a diferença entre os grupos não foi estatisticamente significativa $(p=0,135)$, considerando o nível de significância adotado; mas, por ser esta a questão comparativa principal avaliada no estudo, optou-se por mantê-la no modelo final.

Outra variável mantida no modelo final, apesar de não ter apresentado diferença estatisticamente significativa, foi a idade. Optou-se por mantê-la tendo em vista a importância dessa informação para

explicar a diarreia. A idade confirmou ser um fator importante: as crianças mais novas têm maior chance de desenvolver a morbidade, exceto aquelas que estão em aleitamento materno, pela imunidade passiva transmitida pelo leite e pela diminuição da possibilidade de transmissão de patógenos pela via oral (AZEVEDO, 2003). As crianças doentes estavam na faixa etária mais suscetível à diarreia, menos de 24 meses, conforme Correia e McAuliffe (1999), que relataram que cada mês a mais na vida da criança diminui em 0,98 vez a chance de contrair diarreia, pois o sistema imunológico se desenvolve com o crescimento da criança, aumentando a resistência aos fatores etiológicos da diarreia.

A chance de diarreia nas crianças que tomam vitamina ou fortificante foi 2,34 vezes maior que nas crianças que não tomam. Esse resultado não era esperado, tendo em vista que a prescrição desses suplementos nutricionais tem como objetivo reforçar o organismo da criança. Porém, pode-se conjecturar que as crianças que ingerem o medicamento são justamente aquelas com deficiências antropométricas, situação, por si só, associada à diarreia.

Para interpretar os níveis da questão relacionada ao destino das fraldas sujas de fezes, foi considerada como referência a resposta "as crianças que não utilizam mais fraldas". Descartar as fraldas a céu aberto apresentou elevada chance de se contrair diarreia quando comparada com a referência $(\mathrm{OR}=6,07)$. O destino inadequado das fezes, mesmo que em fraldas, torna a população exposta aos patógenos presentes no material fecal, tendo em vista que as crianças têm o hábito de brincar na área peridomiciliar.

\section{Análise microbiológica da água}

Do total de 100 amostras selecionadas, houve perda de 25\% por problemas analíticos - descontrole da temperatura da estufa de incubação das amostras. Portanto, o número final de amostras analisadas foi de 75 , sendo 35 do grupo cisternas e 40 do grupo outras fontes.

A Tabela 5 apresenta a estatística descritiva das amostras de qualidade da água, tanto para coliformes totais quanto para Escherichia coli — ambos os resultados estão apresentados em Número Mais Provável em 100 mL (NMP/100 mL).

Tabela 4 - Variáveis remanescentes ajustadas no modelo final, por regressão logística.

\begin{tabular}{|c|c|c|c|c|}
\hline \multirow{2}{*}{$\begin{array}{l}\text { Variável } \\
\text { Grupo }^{a}\end{array}$} & \multirow{2}{*}{$\begin{array}{l}\text { Atributos } \\
\text { Cisterna }\end{array}$} & \multicolumn{2}{|r|}{ OR (IC95\%) } & \multirow{2}{*}{$\begin{array}{c}p \\
0,135\end{array}$} \\
\hline & & 0,56 & $(0,260-1,198)$ & \\
\hline $\begin{array}{l}\text { Está tomando } \\
\text { vitamina }^{\mathrm{b}}\end{array}$ & Sim & 2,34 & $(1,112-4,941)$ & 0,025 \\
\hline \multirow{3}{*}{$\begin{array}{l}\text { Destino das } \\
\text { fraldas de } \\
\text { fezes }^{c}\end{array}$} & Fossa/queimada & 2,37 & $(0,857-6,533)$ & 0,096 \\
\hline & Céu aberto & 6,07 & $(2,150-17,151)$ & 0,001 \\
\hline & $\begin{array}{l}\text { Destinos variados (fralda } \\
\text { de pano e descartável) }\end{array}$ & 2,90 & $(1,038-8,094)$ & 0,042 \\
\hline $\begin{array}{l}\text { Idade da } \\
\text { criança }\end{array}$ & Variável contínua & 0,98 & $(0,951-1,003)$ & 0,077 \\
\hline
\end{tabular}


Tabela 5 - Estatística descritiva da qualidade microbiológica da água das amostras provenientes dos dois grupos de abastecimento de água inseridos na pesquisa.

\begin{tabular}{lcccc} 
Amostra & $\begin{array}{c}\text { Coliformes totais } \\
(\mathrm{NMP} / 100 \mathrm{~mL})\end{array}$ & $\begin{array}{c}\text { E. coli } \\
(\mathrm{NMP} / 100 \mathrm{~mL})\end{array}$ & $\begin{array}{c}\text { Coliformes totais } \\
(\mathrm{NMP} / 100 \mathrm{~mL})\end{array}$ & $\begin{array}{c}\text { E. coli } \\
(\mathrm{NMP} / 100 \mathrm{~mL})\end{array}$ \\
Média geométrica & $1,73 \times 10^{1}$ & 4,12 & $2,78 \times 10^{1}$ & 1,39 \\
Mediana & $2,20 \times 10^{1}$ & 4,55 & $5,30 \times 10^{1}$ & 1,50 \\
Mínimo & $\mathrm{ND}$ & $\mathrm{ND}$ & $\mathrm{ND}$ & $\mathrm{ND}$ \\
Máximo $^{\text {a }}$ & $>2,40 \times 10^{3}$ & $>2,40 \times 10^{3}$ & $>2,40 \times 10^{3}$ & $1,30 \times 10^{2}$ \\
Desvio padrão & $7,86 \times 10^{2}$ & $4,12 \times 10^{2}$ & $7,54 \times 10^{2}$ & $2,81 \times 10^{1}$ \\
\hline
\end{tabular}

ND: Não detectado - termo utilizado quando o resultado da análise fica abaixo do limite de detecção da técnica utilizada, que na técnica em questão é de $<1,0 \mathrm{NMP} / 100 \mathrm{~mL}$. "O valor máximo apresentado como "> 2,40 x 10" representa o limite de detecção da técnica; seria necessário a diluição da amostra para obter valor inteiro.

Tabela 6 - Comparação da qualidade microbiológica da água dos grupos cisterna e outras fontes, considerando apenas os resultados de E.coli.

\begin{tabular}{lcccc} 
Variável & Grupo & $\mathrm{n}$ & Mediana & $\mathrm{p}^{*}$ \\
\hline E.coli & Cisternas & 35 & $5,00 \times 10^{\circ}$ & \multirow{2}{*}{0,116} \\
\hline NMP $/ 100 \mathrm{~mL})$ & Outras fontes & 40 & $1,50 \times 10^{\circ}$ & \\
\hline
\end{tabular}

*Teste de Mann-Whitney; p>0,05: a diferença não foi significativa.

As comparações das fontes de água consumida pela população inserida na pesquisa foram feitas baseando-se apenas nos resultados de E. coli, por ser este o microrganismo indicador de contaminação fecal adotado para avaliar a qualidade microbiológica da água, estabelecido pela Portaria no 2.914/2011 (BRASIL, 2011b), que preconiza a ausência de E. coli para a água destinada ao consumo humano (Tabela 5).

Considerando apenas os resultados de E. coli, verificou-se que $23 \%$ das amostras do grupo cisternas estavam em conformidade com o critério de potabilidade estabelecido pela Portaria $n^{\circ} 2.914$, enquanto para o grupo outras fontes esse número foi de $42,5 \%$.

Analisando os resultados da Tabela 6, conclui-se, porém, que não houve diferença estatisticamente significativa, em nível de 5\%, na qualidade da água que ambos os grupos estavam consumindo (Tabela 6).

Em relação às características do abastecimento de água por cisternas para armazenamento de água de chuva, observou-se, nas atividades de campo, que as barreiras sanitárias que auxiliam na manutenção da qualidade da água não estavam sendo amplamente adotadas. Ademais, pelo questionário socioeconômico, verificou-se que aproximadamente 40\% das famílias adicionavam água de outras fontes dentro da cisterna; destas, $43 \%$ faziam isso frequentemente, adotando a cisterna como reservatório e os outros $57 \%$ realizavam esse procedimento apenas quando a água de chuva dentro das cisternas estava acabando. Das 35 amostras de água analisadas, 11 (próximo de 30\%) eram de cisternas que estavam armazenando água de outras fontes com a água de chuva. Essa prática é desaconselhada, tendo em vista que a água de outras fontes encontradas na água rural pode apresentar má qualidade e comprometer a água de chuva armazenada nas cisternas.

A retirada da água era feita com vasilhames (baldes) na maior parte das famílias (80\%), prática que pode contaminar a água armazenada ou mesmo recontaminá-la, considerando que 89\% das famílias faziam o tratamento da água por cloração diretamente na cisterna, porém com dosagens muito variáveis e geralmente distantes das tecnicamente recomendadas. Também deve ser destacado que, mesmo que a quantidade de hipoclorito de sódio empregada fosse adequada, o cloro é volatilizado rapidamente, portanto a possibilidade de contaminação pelos baldes (por exemplo) seria sempre viável, pois não há residual do agente desinfetante. A recomendação é que a desinfecção da água seja feita em domicílio, previamente ao consumo.

\section{Considerações Finais}

Os resultados encontrados no estudo indicaram que a implantação do sistema de captação de água de chuva em cisternas pode não ter sido capaz de proporcionar redução significativa na prevalência de diarreia nas crianças nem melhorias reais na qualidade da água consumida pela população beneficiada quando comparada com as crianças residentes em domicílios nos quais a água consumida era proveniente de outras fontes alternativas, como rios, córregos e minas.

Há questões que devem ser destacadas que podem contribuir para a explicação dos resultados. A diarreia tem sido indicador de saúde mais adotado em estudos sobre impacto de intervenções no saneamento sobre a saúde (HELLER, 1997). No entanto, a variável apresenta problemas na confiabilidade da informação obtida por estar sujeita à interpretação individual da definição da doença quando resultante de questionamento por inquérito (COSTA et al., 2005). Apesar dos cuidados quando da elaboração do protocolo de entrevista, a variável diarreia avaliada por 72 horas pode estar sujeita à interferência do viés de memória, mesmo não tendo sido longo o período a ser recordado. Por ser uma doença aguda e, às vezes, de curta duração, a mesma variável também pode sofrer interferência do viés de prevalência quando no período questionado a criança que estava doente anteriormente já tenha sido curada (TEIXEIRA, 2003). Portanto, a prevalência de diarreia, quando avaliada por 72 horas, pode ter sido baixa pelo curto período de acompanhamento da morbidade.

Também foram detectados hábitos entre as famílias que dispõem do sistema de captação de água de chuva em cisternas no domicílio que podem ter comprometido o resultado: famílias que misturavam água de outras fontes com a água de chuva dentro das cisternas; a falta de adoção das barreiras sanitárias no sistema captação de água 
de chuva; e famílias que não acreditavam na melhor qualidade da água de chuva e preferiram continuar utilizando as fontes de abastecimento anteriormente adotadas para beber e cozinhar, mantendo-se expostas à água de qualidade duvidosa.

Portanto, como conclusão do presente estudo, destaca-se a importância de programas educativos para mudanças de práticas sanitárias das famílias no meio rural. Uma das questões que deve ser abordada é em relação ao tratamento domiciliar da água. Considerando que a adição de água de outras fontes é um procedimento usual entre os beneficiados pelo sistema de captação de água de chuva, deve-se investir em campanhas que ensinem e reforcem a necessidade de tratamento domiciliar da água a ser consumida pela família. A mesma recomendação deve ser transmitida para as famílias que fazem uso de outras fontes alternativas de abastecimento. Para as famílias que utilizam a água de chuva armazenada em cisternas, sugere-se que sejam feitos treinamentos frequentes do uso correto do sistema desde a etapa de captação da água até o momento do consumo domiciliar.

Outro ponto que deve ser enfatizado em campanhas educativas é a higiene pessoal e domiciliar, fatores que têm grande importância na prevenção de doenças, como o hábito de higienização de mãos e de hortaliças cruas antes do consumo, além da correção de práticas sanitárias inadequadas, por exemplo, o descarte de fraldas sujas de fezes a céu aberto ou em rios.

Por ser o sistema de captação de água de chuva uma fonte alternativa individual de abastecimento de água, mas implementada por um programa governamental e que deve beneficiar um milhão de famílias, sugere-se que seja estudada uma forma de controle da qualidade da água armazenada nas cisternas, tendo em vista ser a população beneficiada de baixa renda e escolaridade.

\section{Agradecimentos}

Os autores agradecem ao Conselho Nacional de Desenvolvimento Científico e Tecnológico ( $\mathrm{CNPq}$ ) pelo financiamento da pesquisa por meio do Edital MCT/CT-HIDRO/CT-SAÚDE/CNPq no 45/2008 - "Seleção Pública de Propostas para Apoio a Projetos de Pesquisa Relacionados à Água e Saúde Pública”. Também agradecem à Fundação de Amparo à Pesquisa do Estado de Minas Gerais (FAPEMIG) pela disponibilização da bolsa em nível de Doutorado para a primeira autora do artigo.

\section{Referências}

AMARAL, L.A.; NADER FILHO, A.; ROSSI JR, O.D.; FERREIRA, F.L.A.; BARROS, L.S.S. (2003) Água de consumo humano como fator de risco à saúde em propriedades rurais. Revista de Saúde Pública, v. 37, n. 4, p. 10-514.

AMERICAN PUBLIC HEALTH ASSOCIATION; AWWA; WEF. (2005) Standard methods for the examination of water and wastewater. 21 ed. Washington: APHA, 2005.

AMORIM, M.C.C. \& PORTO, E.R. Avaliação da Qualidade Bacteriológica das Águas de Cisternas: Estudo de Caso no Município de Petrolina PE. In: Simpósio Brasileiro de Captação de Água de Chuva, 3., 2001. Campina Grande-PB: ABCMAC. Resumos... Campina Grande-PB: ABCMAC, 2001.

AZEVEDO, E.A. (2003) Exclusão sanitária em Belo Horizonte - MG: caracterização e associação com indicadores de saúde. 181 f. Dissertação (Mestrado em Saneamento, Meio Ambiente e Recursos Hídricos) - Escola de Engenharia da Universidade Federal de Minas Gerais, Belo Horizonte.

BRASIL.(2004) Secretaria Nacional de Saneamento Ambiental. Sistema Nacional de Informação sobre Saneamento. Brasília, 2004.

BRASIL. Ministério das Cidades. (2011a) Plano Nacional de Saneamento Básico - PLANSAB. 2011. Disponível em: <http://www.cidades.gov.br/ index. php?option =com_content \&view $=$ article $\&$ id $=736$ : brasil-tera-seuplano-nacional-de-saneamento-basico-em-2011\&catid $=84 \&$ ltemid $=$ 113 >. Acesso em: jun. 2011.

BRASIL. Ministério da Saúde. (2011b) Portaria $n^{\circ}$ 2.914, de 12 de dezembro de 2011. Estabelece os procedimentos e responsabilidades relativas ao controle e vigilância da qualidade da água para consumo humano e seu padrão de potabilidade, e dá outras providências.

BRITO, L.T.; PORTO, E.R.; SILVA, A.S.; SILVA, M.S.L.; HERMES, L.C.; MARTINS, S.S. (2005a) Avaliação das características fisico-químicas e bacteriológicas das águas das cisternas da comunidade de Atalho, Petrolina-PE. In: Simpósio Brasileiro de Captação e Manejo de Água de Chuva. Captação e Manejo de Água de Chuva, 5., 2005. Teresina-PI: ABCMAC. Resumos... Teresina-PI: ABCMAC.

BRITO, L.T.L.; ANJOS, J.B.; PORTO, E.R.; SILVA; A.S.; SOUZA, M.A.; XENOFONTE, G.H.S. (2005b) Qualidade físico-química e bacteriológica das águas de cisternas no município de Ouricuri, PE. In: Simpósio Brasileiro de Captação e Manejo de Água de Chuva. Captação e Manejo de Água de Chuva, 5., 2005. Teresina, PI: ABCMAC. Resumos... Teresina, PI: ABCMAC.

CLASEN, T.; SCHMIDT, W.P.; RABIE, T.; ROBERTS, I.; CAIRNCROSS, S. (2007) Interventions to improve water quality for preventing diarrhoea: systematic review and meta-analysis. BMJ, p. 334-782.

CORREIA, L.L. \& McAULIFFE, J.F. (1999) Saúde maternoinfantil. In: ROUQUAYROL, Z. \& ALMEIDA FILHO, N. Epidemiologia e saúde. 5. ed. Rio de Janeiro: Medsi, 1999. p. 375-403.

COSTA, S.S.; HELLER, L.; BRANDÃO, C.C.S.; COLOSIMO, E.A. (2005) Indicadores epidemiológicos aplicáveis a estudos sobre a associação entre saneamento e saúde de base municipal. Revista Engenharia Sanitária e Ambiental, v. 10, n. 2, p. 118-127. 
DIAS, A.V.F. (2004) Complexidade, desenvolvimento sustentável, comunicação - o Programa Um Milhão de Cisterna em comunidades do Ceará. 200f. Dissertação (Mestrado em Desenvolvimento e Meio Ambiente) - Universidade Federal do Ceará, Fortaleza, Ceará.

ESREY, S.A.; FEACHEM, R.G.; HUGHES, J.M. (1985) Interventions for the control of diarrhoeal diseases among young children; improving water supplies and excreta disposal facilities. Bulletin of the World Health Organization, Switzerland, v. 63, p. 757-772.

ESREY, S.A.; POTASH, J.B.; ROBERTS, L.; SHIFF, C. (1991) Effects of improved water supply and sanitation on ascariasis, diarrhea, dracunculiasis, hookworm infection, schistosomiasis and trachoma. Bulletin of the World Health Organization, Switzerland, v. 59, n. 5, p. 609-621.

FEWTRELL, L; KAUFMANN, R.B.; KAY, D.; ENANORIA, W.; HALLER, L.; COLFORD, J.M. JR. (2005) Water, sanitation, and hygiene interventions to reduce diarrhea in less developed countries: a systematic review and meta-analysis. Lancet Infection Disease, v. 5, n. 1, p. 42-52.

HELLER, L. (1997) Saneamento e saúde. Brasília: Organização Pan Americana de Saúde/ Organização Mundial da Saúde.

JOVENTINO, E.S. SILVA, S.F.; ROGERIO, R.F.; FREITAS, G.L.; XIMENES, L.B.; MOURA, E.R.F. (2010) Comportamento da diarréia infantil antes e após consumo pluvial em municípios do semi-árido brasileiro. Texto Contexto Enfermagem, v. 19, n. 4, p. 691-699.

LUNA, C.F. (2011) Avaliação do impacto do Programa Um Milhão de Cisternas Rurais (P1MC) na saúde: ocorrência de diarréia no Agreste Central de Pernambuco. 207 f. Tese (Doutorado em Saúde Pública) - Centro de Pesquisas Aggeu Magalhães, Fundação Oswaldo Cruz, Pernambuco.

MALHEIROS, P.S.; SCHÄFER, D.F.; HERBERT, I.M.; CAPUANI, S.M.; SILVA, E.M.; SARDIGLIA, C.U. (2009) Contaminação bacteriológica de águas subterrâneas da região oeste de Santa Catarina, Brasil. Rev. Inst. Adolfo Lutz, São Paulo, v. 68, n. 2, p. 305-8.

MARCYNUK, P.; FLINT, J.; SARGEANT, J.; JONES, A.; COSTA, A.M.; BRITO, A.M.; THOMAS, M.K.; MUCHAAL, P.K.; SZILASSY, E.; LAPA, T.M.; LUNA, C.; ALMEIDA, Y.; RAUPP, L.; CHANG, K.; PEREZ, E. (2009) Preliminary summary: prevalence of diarrhoea among cistern and non cistern users in Northeast Brazil and further risk factors and prevention strategies. In: Simpósio Brasileiro de Captação de Água de Chuva no Semi-Árido, 7. Caruaru, PE. Anais... Caruaru, PE (anais eletrônicos).

MORAES, L.R.S. (1997) Avaliação do impacto sobre a saúde das ações de saneamento ambiental em áreas pauperizadas de Salvador - Projeto AISAM. In: HELLER, L.; MORAES, L.R.S.; MONTEIRO, T.C.N.; SALLES, M.J.; ALMEIDA, L.M.; CÂNCIO, J. (orgs.) Saneamento e saúde em países em desenvolvimento. Rio de Janeiro: CC\&P, 1997. p. 281- 305.

ROCHA, C.M.B.M.; RODRIGUES, L.S.; COSTA, C.C.; OLIVEIRA, P.R.; SILVA, I.J.; JESUS, E.F.M.; ROLIM, R.G. (2006) Avaliação da qualidade da água e percepção higiênico-sanitária na área rural de Lavras, Minas Gerais, Brasil, 1999-2000. Cad. Saúde Pública, Rio de Janeiro, v. 22, n. 9, p. 1967-1978.

RODRIGO, S.; SINCLAIR, M.; CUNLIFFE, D.; LEDER, K. (2003) A Critica Assessment of Epidemiological Studies for the Investigation of the Health Risk of Drinking Untreated Rainwater. In: Proceedings of The $13^{\text {th }}$ International Rainwater Catchment Systems Conferece. México, 2003.

SILVA, C.V. (2006) Qualidade da água de chuva para consumo humano armazenada em cisternas de placas: Estudo de caso: Araçuaí, MG. 117 f. Dissertação (Mestrado em Saneamento, Meio Ambiente e Recursos Hídricos) - Escola de Engenharia, Universidade Federal de Minas Gerais, Belo Horizonte.

SIMMONS, G.; HOPE, V.; LEWIS, G.; WHITMORE, J.; GAO, W. (2001) Contamination of potable roof-collected rainwater in Auckland, New Zealand. Water Research, v. 35, n. 6, p. 1518-1524.

TEIXEIRA, J.C. (2003) Associação entre cenários de saneamento e indicadores de saúde em crianças: estudo em áreas de assentamento subnormal em Juiz de Fora, MG. 278 f. Tese (Doutorado em Saneamento, Meio Ambiente e Recursos Hídricos) - Escola de Engenharia da Universidade Federal de Minas Gerais, Belo Horizonte.

WORLD HEALTH ORGANIZATION. (1988) Persistent diarrhea in children in developing countries: Memorandum from a WHO Meeting. Bulletin of the World Health Organization, v. 66, n. 6, p. 709-717.

WORLD HEALTH ORGANIZATION. (2009) Diarrhea: Why children are still dying and what can be done. Disponível em: <http://whqlibdoc.who.int/ publications/2009/9789241598415 eng.pdf>. Acesso em: 7 jun. 2011. 